\title{
Concerns about the antidepressant-like effects of high-dose ketamine in mice
}

\author{
Jianjun Yang $\cdot$ Zhiqiang Zhou $\cdot$ Chun Yang
}

Received: 22 March 2011 /Accepted: 3 April 2011 /Published online: 19 April 2011

(C) Springer-Verlag 2011

We read with great interest the recent article $C D-1$ and Balb/cJ mice do not show enduring antidepressant-like effects of ketamine in tests of acute antidepressant efficacy by Bechtholt-Gompf et al. (in press). In that study, the tail suspension test (TST) and forced swimming test (FST) were not sensitive to long-lasting antidepressant-like effects of ketamine in mice. We appreciate this study and would like to discuss an issue relevant to this article.

The authors administrated high-dose ketamine to observe the behavioral changes in the FST and TST. However, the administration of ketamine $25 \mathrm{mg} / \mathrm{kg}$ induces an immediate behavioral activation, characterized by hyperlocomotion, stereotypies, and ataxia in rats (Razoux et al. 2007), suggesting that ketamine exceeding $25 \mathrm{mg} / \mathrm{kg}$ tends to elicit schizophrenia-like manifestations. Similarly, in that study, the authors did not investigate the motor behavior before FST and TST. Although a citation was provided by the authors in the discussion that the effective dose $(10,50 \mathrm{mg} /$ $\mathrm{kg}$ ) of ketamine, instead of high dose, did not affect general locomotor activity, in either the plus-maze or the open field test (Engin et al. 2009). On the other hand, low-dose ketamine was commonly used to investigate its antidepressant effect in experimental studies and was recommended to ameliorate the symptoms of patients with depression (Machado-Vieira et al. 2009). Thus, we assumed that highdose ketamine may be not very suitable to investigate its antidepressant effect.

\section{References}

Bechtholt-Gompf AJ, Smith KL, John CS, Kang HH, Carlezon WA Jr, Cohen BM, Ongür D (2011) CD-1 and Balb/cJ mice do not show enduring antidepressant-like effects of ketamine in tests of acute antidepressant efficacy. Psychopharmacology (Berl) (in press)

Engin E, Treit D, Dickson CT (2009) Anxiolytic- and antidepressantlike properties of ketamine in behavioral and neurophysiological animal models. Neuroscience 161:359-369

Machado-Vieira R, Salvadore G, Diazgranados N, Zarate CA Jr (2009) Ketamine and the next generation of antidepressants with a rapid onset of action. Pharmacol Ther 123:143-150

Razoux F, Garcia R, Léna I (2007) Ketamine, at a dose that disrupts motor behavior and latent inhibition, enhances prefrontal cortex synaptic efficacy and glutamate release in the nucleus accumbens. Neuropsychopharmacology 32:719-727

J. Yang $\cdot$ Z. Zhou $\cdot$ C. Yang $(\bowtie)$

Department of Anesthesiology, Jinling Hospital,

School of Medicine, Nanjing University,

Nanjing, China

e-mail: yangchuntz@sina.com 